\title{
Direct Effect of Glibenclamide on Guanylate Cyclase Activity in the Rat In Vitro
}

\author{
D. L. Vesely \\ Division of Endocrinology and Metabolism, University of Arkansas for Medical Sciences, Little Rock, Arkansas, USA
}

\begin{abstract}
Summary. Glibenclamide enhanced the activity in the rat of guanylate cyclase in a number of extra-pancreatic tissues. Thus, glibenclamide enhanced guanylate cyclase activity in vitro two- to threefold in liver, kidney, heart, spleen and colon at a concentration of $1 \mu \mathrm{mol} / \mathrm{l}$. Dose-response curves of glibenclamide on hepatic guanylate cyclase revealed that more than half-maximal stimulation was observed at a concentration as low as $10 \mathrm{nmol} / 1(p<0.001)$ and no stimulation of guanylate cyclase was seen when the concentration was decreased to $1 \mathrm{nmol} / 1$. Maximal enhancement was seen at $100 \mathrm{nmol} / 1$ of glibenclamide. Varying the concentration of the guanylate cyclase co-factor manganese had no effect on the glibenclamide enhancement of guanylate cyclase. In addition to the increased insulin receptors found recently in monocytes and fibroblasts, the present findings may help explain the extra-pancreatic effects of glibenclamide and possibly of other sulphonylurea drugs.
\end{abstract}

Key words: Oral hypoglycaemic agent, glibenclamide, cyclic GMP, guanylate cyclase.

Glibenclamide has been reported to be 1000 times more effective than tolbutamide in man [1]. Glibenclamide has effects on both the pancreas [2-4] and extra-pancreatic tissues $[5,6]$, but its mechanisms of action have not been completely elucidated. Clinical studies have suggested that glibenclamide may improve diabetic control and improve glucose tolerance through a mechanism other than increased insulin secretion $[7,8]$. In the peripheral tissues of diabetic animals, insulin enhances the activity of guanylate cyclase (E.C. 4.6.1.2), the enzyme that catalyzes the production of cyclic GMP [9]. The present investigation was designed to determine if glibenclamide, like insulin, might have a direct effect on extra-pancreatic guanylate cyclase activity.

\section{Materials and Methods}

\section{Animals}

Tissues used in these experiments were obtained from male Sprague-Dawley rats weighing $150-200$ g. These animals had been maintained on Purina laboratory chow and tap water ad libitum.

\section{Materials}

Glibenclamide (glyburide) was dissolved immediately before use in triple-distilled water to make the concentrations specified below. Alumina, neutral activity I for the column chromatography, was obtained from Merck, Darmstadt, FGR. The $\left[\alpha^{32} \mathrm{P}\right]$-guanosine triphosphate was from International Chemical and Nuclear Corporation, Irvine, California, USA.

\section{Guanylate Cyclase Assay}

Guanylate cyclase activity was measured as described previously $[9,10]$. The various tissues were homogenized in cold $0.03 \mathrm{~mol} / 1$ Tris $\mathrm{HCl}(\mathrm{pH} 7.6)$ and then centrifuged at $37,000 \times g$ at $4{ }^{\circ} \mathrm{C}$ for $15 \mathrm{~min}$. When centrifuged at $37,000 \times g$, over $95 \%$ of guanylate cyclase activity was in the supernatant. The supernatant, to which glibenclamide had been added to obtain the final concentrations noted in the text, was then assayed at $37^{\circ} \mathrm{C}$ for $10 \mathrm{~min}$ for guanylate cyclase activity. The reaction mixture contained final concentrations of Tris $\mathrm{HCl} 20 \mathrm{mmol} / \mathrm{p}, \mathrm{pH} 7.6 ; \mathrm{MnCl}_{2} 4 \mathrm{mmol} / 1$; cyclic GMP $2.67 \mathrm{mmol} / 1$ (used to minimize destruction of $\left[{ }^{32} \mathrm{P}\right]$-cyclic GMP) and a guanosine triphosphate regenerating system (creatine phosphate $5 \mathrm{mmol} / \mathrm{l}$; creatine phosphokinase $11.25 \mathrm{U}$ [E.C. 2.7.3.2.]). Also included in the reaction mixture were bovine serum albumin $100 \mathrm{ug}$; caffeine $20 \mathrm{mmol} / 1$; [ $\left.{ }^{32} \mathrm{P}\right]-G T P 1.2 \mathrm{mmol} / \mathrm{l}$, approximately $5 \times 10^{5} \mathrm{cpm}$; and the enzyme preparation having 0.1 to $0.2 \mathrm{mg} / \mathrm{ml}$ protein. The volume of the supernatant fraction used was $25 \mu \mathrm{l}$ and the final volume of the cyclase assay, which includes the above supernatant fraction, the reaction mix and the radioisotopes, was $75 \mu 1$. The reaction was terminated by the addition of $10 \mu \mathrm{l}$ of 


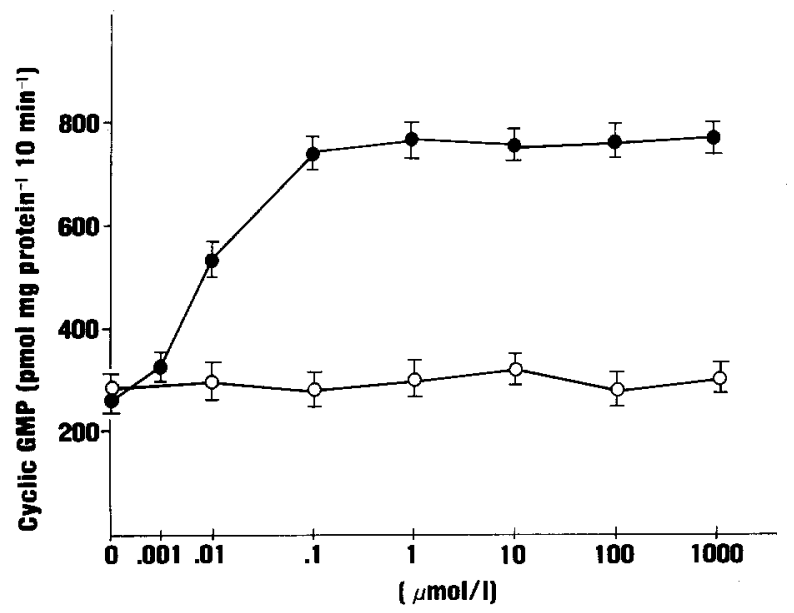

Fig. 1. Dose-response curve of glibenclamide on hepatic guanylate cyclase activity in the rat. Each value is the mean \pm SEM of triplicate samples performed on three animals in each group and repeated in three separate experiments $(n=9)$. The values at $10 \mathrm{nmol} / 1$ (and higher concentrations) were significant at $p<0.001$ compared with control using Student's t test for unpaired values. $=$ glibenclamide; $O=$ control without glibenclamide

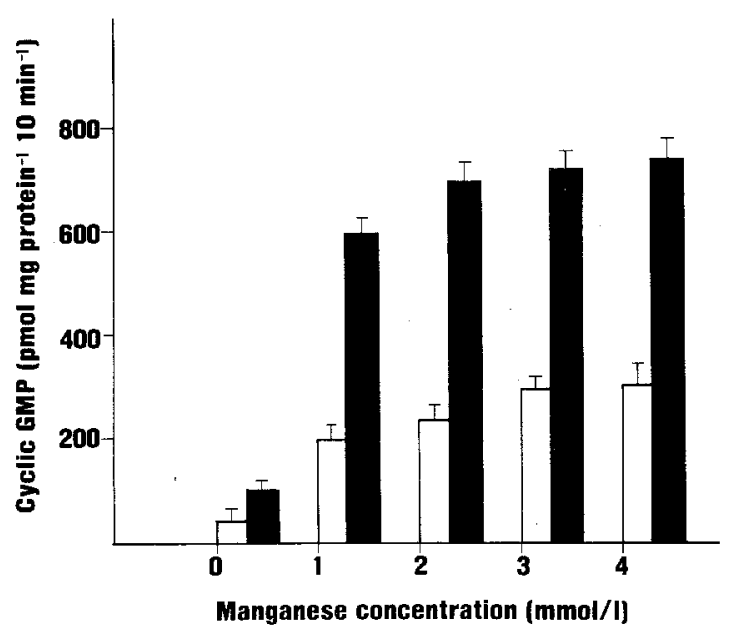

Fig. 2. The effect of varying the manganese concentrations on glibenclamide (at a concentration of $100 \mathrm{nmol} / \mathrm{l}$ ) enhancement of hepatic guanylate cyclase activity. Varying the concentration of the guanylate cyclase co-factor manganese had no effect on glibenclamide enhancement of guanylate cyclase activity except that a less maximal activation was seen at the 0 versus the higher concentrations of manganese. Each bar is the mean \pm SEM of triplicate samples performed on three animals in each group in three separate experiments. $\square=$ without glibenclamide; $\boldsymbol{\square}=$ with glibenclamide

$0.1 \mathrm{~mol} / \mathrm{L}$ EDTA (pH 7.6) containing about $30000 \mathrm{cpm}$ of $\left[{ }^{3} \mathrm{H}\right]-\mathrm{cy}-$ clic GMP (to estimate recovery in the subsequent steps) and then heating at $100^{\circ} \mathrm{C}$ for $3 \mathrm{~min}$. After cooling in an ice bath, the $\left[{ }^{32} \mathrm{P}\right] \mathrm{cy}-$ clic GMP formed was isolated by sequential chromatography on Dowex-AG $50 \mathrm{~W}-\mathrm{X} 4 \mathrm{H}^{+}(200-400$ mesh) and alumina using the modification previously described in detail [10]. The overall recovery of cyclic GMP after the two-stage chromatographic procedure was $95 \%$. Blank [ $\left.{ }^{32} \mathrm{P}\right]$-counting rates averaged $40-50 \mathrm{cpm}$. With
Table 1. Direct effect of glibenclamide on guanylate cyclase activity in the rat in a variety of tissues

\begin{tabular}{lrrr}
\hline & \multicolumn{3}{l}{ Cyclic GMP $\left(\mathrm{pmol} \cdot \mathrm{mg} \mathrm{protein}^{-1} \cdot 10 \mathrm{~min}^{-1}\right)$} \\
\cline { 2 - 4 } Tissue & Control & Glibenclamide $(1 \mu \mathrm{mol} / \mathrm{l})$ & \multicolumn{1}{l}{$p^{\mathrm{a}}$} \\
\hline Liver & $288 \pm 11$ & $720 \pm 14$ & $<0.001$ \\
Kidney & $301 \pm 13$ & $899 \pm 21$ & $<0.001$ \\
Pancreas & $184 \pm 9$ & $371 \pm 10$ & $<0.001$ \\
Colon & $694 \pm 12$ & $1429 \pm 19$ & $<0.001$ \\
Spleen & $610 \pm 13$ & $1398 \pm 23$ & $<0.001$ \\
Heart & $157 \pm 10$ & $344 \pm 15$ & $<0.001$ \\
\hline
\end{tabular}

Values represent the mean \pm SEM of triplicate samples performed on three animals in each group in three separate experiments $(n=9)$

Significance of comparison with control was determined by the Student's $t$ test for unpaired values

this assay system, cyclic GMP production was linear with time for $20 \mathrm{~min}$ and with added protein from $50-200 \mu \mathrm{g}$. All of the ${ }^{32} \mathrm{P}$-containing material was identifiable as cyclic GMP as determined by thin-layer chromatography on PEI-cellulose (Brinkman) with LiCl $1 \mathrm{~mol} / \mathrm{l}$ as solvent and on Chromar sheets (Mallinckrodt Chemical Works, St. Louis, Missouri, USA) developed with absolute alcohol and concentrated $\mathrm{NH}_{4} \mathrm{OH}(5: 2 \mathrm{v} / \mathrm{v})$. Glibenclamide was added to the supernatant without pre-incubation. Each assay was conducted in triplicate and the results confirmed in three separate experiments.

\section{Statistical Analysis}

All data are presented as mean \pm SEM. The statistical comparison between groups with and without glibenclamide and those with varying concentrations of manganese were done by the Student's ' $t$ ' test for unpaired groups.

\section{Results}

\section{Effect of Glibenclamide on Guanylate Cyclase}

Glibenclamide enhanced rat guanylate cyclase activity in a wide variety of tissues (Table 1). It caused a two-to-threefold enhancement of guanylate cyclase activity in liver, kidney, colon, spleen, pancreas and heart $(p<0.001$ for each). The order of maximal responsiveness of guanylate cyclase activity to glibenclamide at a concentration of $1 \mu \mathrm{mol} / 1$ was kidney $>$ heart $>$ colon $>$ spleen $>$ pancreas. The dose-response curve of hepatic guanylate cyclase activity is seen in Figure 1. More than half-maximal stimulation was observed at concentrations of glibenclamide as low as $10 \mathrm{nmol} / \mathrm{l}(p<0.001)$. No stimulation of guanylate cyclase was seen when the concentration was decreased to $1 \mathrm{nmol} / 1$. Maximal enhancement was seen at $100 \mathrm{nmol} / 1$ of glibenclamide: no further enhancement was observed increasing the concentration to the $\mu \mathrm{mol} / 1$ or $\mathrm{mmol} / 1$ range. 


\section{Effect of Varying Manganese Concentration on Glibenclamide Enhancement of Guanylate Cyclase}

It has recently been reported that certain agents have no effect on guanylate cyclase activity under normal circumstances, but only when the manganese content is absent from the incubation mixture [11]. A series of experiments was performed to determine whether the concentration of guanylate cyclase co-factor manganese affected the glibenclamide activation of guanylate cyclase (Fig.2). Varying the concentration of manganese had no significant effect on glibenclamide enhancement of guanylate cyclase activity except that decreased maximal activation of the enzyme was seen when manganese was absent from the incubation mixture.

\section{Discussion}

In the present investigation, glibenclamide enhanced the activity of guanylate cyclase in a number of peripheral tissues. This enhancement was seen at or below concentrations considered to be in the therapeutic range [6]. There are a number of clinical studies suggesting an extrapancreatic effect of glibenclamide $[7,8]$. One of the most recent of these studies [8] demonstrated that, although glibenclamide is known to increase insulin secretion from the pancreas [2-4], there is no response to glibenclamide in vivo unless a meal is also given. This same study revealed that insulin secretion was not significant until $1 \mathrm{~h}$ after a combined meal and glibenclamide, but there was a progressive fall in blood glucose which became significant $45 \mathrm{~min}$ after glibenclamide administration [8]. These studies suggest that blood glucose can decrease significantly before insulin secretion increases [8]. At the cellular level glibenclamide has recently been shown to increase the number of insulin receptors in vivo in monocytes [5] and in vitro in fibroblasts [6]. Although insulin is known to enhance guanylate cyclase activity in peripheral tissues in diabetic animals [9], the present investigation in vitro would suggest that glibenclamide can have a direct effect on peripheral tissues without utilizing insulin to mediate its effect. Evidence against the present findings, being mediated via increased numbers of insulin receptors, is the fact that there was no insulin present in these experiments to cause the enhancement of guanylate cyclase observed. Thus, glibenclamide could not be enhancing the enzyme by causing an increased interaction of insulin with its receptor.

It appears, therefore, that glibenclamide may have at least three effects: (1) It increases insulin release from the pancreas $[2,4,8],(2)$ it increases insulin re- ceptors in peripheral tissues [5, 6], and (3) it has a direct effect on at least one enzyme (guanylate cyclase) in peripheral tissues. This last effect is similar to the effect of insulin at the cellular level in diabetic animals in that both exogenous [9] and endogenous [12] insulin increase the activity of the enzyme guanylate cyclase in peripheral tissues to a similar extent as was seen with glibenclamide in the present investigation.

Although the direct benefit of glibenclamide enhancing guanylate cyclase activity to the patient with diabetes cannot be determined from the present investigation in vitro it has been shown previously that the enhancement of guanylate cyclase activity by endogenous insulin is associated with decreased basal hepatic glucose output, gluconeogenesis, and urea production in perfused rat livers [12]. Whether or not cyclic GMP is a 'second messenger' for some aspects of the action of glibenclamide remains to be determined.

Indirect evidence that the effect of glibenclamide on guanylate cyclase activity is not secondary to the decrease in blood glucose induced by the drug is that it takes $30-45 \mathrm{~min}$ for glibenclamide to lower blood glucose significantly [8], while the present findings were seen at $10 \mathrm{~min}$. Direct evidence that glucose is not necessary for the effect of glibenclamide on guanylate cyclase activity is that no glucose or sucrose was present during these experiments in vitro. The effects of insulin on guanylate cyclase activity are similarly not secondary to the reduction of blood glucose by insulin. Insulin given in vivo can restore guanylate cyclase activity to control levels (non-diabetic) in $5 \mathrm{~min}$, a period of time in which there is no decrease in the blood glucose measured in the same animals [9]. Thus, the effect of both insulin and glibenclamide on guanylate cyclase activity in peripheral tissues precedes any reduction in blood glucose.

With regard to cyclic nucleotide metabolism, there appears to be only one other investigation with glibenclamide [13]. In that study, which was performed only on fat cells, the authors concluded that the antilipolytic action of glibenclamide was independent of cyclic AMP levels, although there was some inhibition of the low $\mathrm{K}_{\mathrm{m}}$ cyclic AMP phosphodiesterase of fat cells [13]. The drug's effects on cyclic GMP metabolism were not studied in that investigation [13]. Other sulphonylureas have been noted to inhibit cyclic AMP phosphodiesterases in peripheral tissues [14-16] and to increase adenylate cyclase activity in rabbit and human heart [17]. Whether further investigation will reveal an effect of glibenclamide on some aspect of cyclic AMP metabolism remains to be determined, but it should be noted that glibenclamide differs significantly from the older sulphonylureas with the addition of a benzamide radical to the classi- 
cal benzelsulphonylurea grouping. In diabetic animals, cyclic AMP levels have been noted to be elevated and to decrease to normal (control levels) with insulin treatment [18]. Thus, the increasing of cyclic AMP levels by oral agents would appear more compatible with the deleterious effects of these agents rather than the anti-diabetic effects as suggested previously by Lasseter et al. [17]. Insulin and insulin-like effects, on the other hand, appear to be mediated by the guanylate cyclase-cyclic GMP system $[9,12]$. Thus, if glibenclamide were to have insulin-like effects in peripheral tissues one might expect that the guanylate cyclase-cyclic GMP system would be more likely to be involved, as was seen in the present investigation.

Finally, with respect to the mechanism by which glibenclamide interacts with the enzyme guanylate cyclase, it has been reported recently that the guanylate cyclase co-factor manganese may play an important role in the enzyme's interaction with various agents [11]. Superoxide dismutase had no effect on guanylate cyclase activity under normal circumstances but did have an effect when manganese was absent from the incubation mixture [11]. Varying the concentration of manganese had no effect on the enhancement of guanylate cyclase activity in the present investigation. Thus, the stimulation of guanylate cyclase activity by glibenclamide appears to take place with both low and optimal concentrations of the cofactor for the enzyme.

Acknowledgements. I would like to thank Ms. J.Gray for her excellent technical assistance and M. Morrison for her valuable secretarial assistance. Glibenclamide (glyburide) was kindly provided by D. L. Skold, Upjohn, Kalamazoo, Michigan, USA.

\section{References}

1. Schmidt FH, Stork H, Bander A, Pfaff W (1969) Concerning the pharmacodynamics of HB 419. Horm Metab Res Suppl Series $1: 25-33$

2. Westman S, Hellerstrom C (1970) The metabolism of pancreatic beta-cells of mice in the presence of hypoglycemic sulphonylureas. Postgrad Med J 46: (Suppl) 28--31

3. Weinges KF (1970) Comparative studies of the effects of glibenclamide and tolbutamide on insulin release from isolated rat islets in vitro. Postgrad Med J 46 (Suppl): 32-35

4. Efendic S, Enzmann F, Nylen A, Uvnas-Wallensten K, Luft R (1979) Effect of glucose/sulfonylurea interaction on the release of insulin, glucagon, and somatostatin from isolated perfused rat pancreas. Proc Natl Acad Sci USA 76: 5901-5904
5. Beck-Nielsen H, Pedersen O, Lindskov HO (1979) Increased insulin sensitivity and cellular insulin binding in obese diabetes following treatment with glibenclamide. Acta Endocrinol 90: $451-462$

6. Prince MJ, Olefsky MJ (1980) Direct in vitro effect of a sulfonylurea to increase human fibroblast insulin receptors. J Clin Invest 66:608-611

7. Feldman JM, Lebovitz HE, Lebovitz FL (1971) Endocrine and metabolic effects of glybenclamide - evidence for an extrapancreatic mechanism of action. Diabetes 20:745-755

8. Sartor G, Melander A, Schersten B, Wahlin-Boll E (1980) Serum glibenclamide in diabetic patients, and influence of food on the kinetics and effects of glibenclamide. Diabetologia 18: $17-22$

9. Vesely DL, Castro A, Levey GS (1977) Decreased rat hepatic guanylate cyclase activity in streptozotocin-induced diabetes mellitus. Diabetes 26:308-313

10. Vesely DL (1979) Testosterone, its precursors and metabolites enhance guanylate cyclase activity. Proc Natl Acad Sci USA 76: 3491-3494

11. Mittal CK, Murad F (1977) Activation of guanylate cyclase by superoxide dismutase and hydroxyl radical: A physiologic regulator of guanosine $3^{\prime}, 5^{\prime}$ monophosphate formation. Proc Natl Acad Sci USA 76:4360-4364

12. Vesely DL, Selawry H, Levey GS (1979) Correction of decreased guanylate cyclase activity in diabetic rats by pancreatic islet transplantation. Transplantation 27: 403-405

13. Ebert R, Hillebrandt O, Schwabe U (1974) Role of calcium and cyclic adenosine $3^{\prime}, 5^{\prime}$-monophosphate in the antilipolytic effect of tolbutamide and glibenclamide. Naunyn-Schmiedeberg's Arch Pharmacol 286: 181-194

14. Chaudhuri TK, Winer N (1970) Effect of chlorpropamide on renal phosphodiesterase. J Lab Clin Med 76: 863 (Abstract)

15. Brooker G, Fichman M (1971) Chlorpropamide and tolbutamide inhibition of adenosine $3^{\prime}, 5^{\prime}$ cyclic monophosphate phosphodiesterase. Biochem Biophys Res Commun 42:824-828

16. Goldfine ID, Perlman R, Roth J (1971) Inhibition of cyclic 3', $5^{\prime}$ AMP phosphodiesterase in islet cells and other tissue by tolbutamide. Nature 234: 295-297

17. Lasseter KD, Levey GS, Palmer R, McCarthy JS (1972) The effect of sulfonylurea drugs on rabbit myocardial contractility, canine purkinje fiber automaticity, and adenyl cyclase activity from rabbit and human hearts. J Clin Invest 51: 2429-2434

18. Jefferson LS, Exton JH, Butcher RW, Sutherland EW, Park CR (1968) Role of adenosine $3^{\prime}, 5^{\prime}$-monophosphate in the effects of insulin anti-insulin serum on liver metabolism. $J$ Biol Chem 243: 1031-1038

Received: 7 May 1981

and in revised form: 9 October 1981

David L. Vesely, M.D., Ph.D.

Division of Endocrinology and Metabolism

University of Arkansas for Medical Sciences

4301 West Markham

Little Rock, Arkansas, 72205, USA 